\title{
Um lugar para chamar de seu: A luta dos negros barbadianos pela moradia no Pós-Abolição
}

Elaine P. Rocha ${ }^{1}$

Resumo: A conquista da liberdade no Caribe inglês se deu meio século antes da abolição da escravidão no Brasil, porém, assim como no Brasil e nos Estados Unidos, a emancipação do trabalhador não significou grande progresso em sua situação econômica e social. Os libertos foram deixados, na maior parte dos casos, sem casas e sem terras para trabalhar, com sua liberdade tolhida em diferentes maneiras, por leis, normas ou costumes. Ao estudar o caso da ilha de Barbados e a luta dos negros barbadianos por moradia e trabalho no Pós-Abolição, procura-se desvendar as dinâmicas de controle dos trabalhadores negros e as estratégias por estes construídas para escaparem ao controle dos patrões e da elite. Neste artigo, a luta pela moradia e pela posse da terra é examinada em conexão a outros fatores, tais como extensão territorial, lutas políticas e o desenvolvimento de um sistema de educação mais inclusivo, passando pelas migrações negras e distinções de gênero.

Palavras-Chave: Pós-Abolição, moradia, educação, Caribe, Barbados, trabalho

\section{A Place to call their own: the struggle of Black Barbadians for housing during the Post-Abolition period}

\begin{abstract}
The emancipation of slavery in the English Caribbean occurred half a century before the abolition in Brazil, but, as in Brazil and in the United States of America, the emancipation of workers did not mean great progress in their economic and social situation. The freedmen

\footnotetext{
${ }^{1}$ Bacharel e licenciada em História pela Universidade de Taubaté (UNITAU); Mestre em História pela Pontificia Universidade Católica de São Paulo (PUC-SP); Mestre em História Cultural pela University of Pretoria (África do Sul) e Doutora em História Social pela Universidade de São Paulo. Professora Associada do Departamento de História e Filosofia da University of the West Indies (UWI). Autora dos livros: Mundos do trabalho e dos trabalhadores: experiências e vivências no Brasil e no Caribe, org. com Thiago Reis e Leonardo Matos Silva (2018); Another Black Like Me: The Construction of identities and Solidarity in the African Diaspora org. com Nielson Bezerra (2015); Racism in Novels: a Comparative Study of Brazilian and South African Cultural History (2010); Saci Perere, O Vento da Liberdade”(2000). Email: elaine.rocha@cavehill.uwi.edu
}

\section{SANPHLAC}


were left, in most cases, without housing and without land to work, with their freedom hindered in different ways by laws, norms or customs. In studying the case of the island of Barbados and the struggle of Black Barbadians for housing and work in the Post-Abolition, this study seeks to unravel the dynamics of control of black workers and the strategies they have built to escape the control of planters and the elite. In this article, the struggle for housing and land ownership is examined in connection with other factors such as territorial extension, political struggles, and the development of a more inclusive education system, it also includes Black migrations and gender distinctions.

Keywords: Post-Abolition, housing, education, Caribbean, Barbados, labor.

Artigo recebido em: 28/06/2019

Artigo aprovado para publicação em: 28/10/2019

\section{Introdução}

Um dos pontos mais sensíveis nas sociedades colonizadas, onde a maioria da população era dominada por uma pequena oligarquia, é a posse da terra e, por extensão, a questão da habitação para a população trabalhadora. Com o fim da escravidão, a questão da propriedade de terras em sociedades marcadas pelo latifúndio e uso quase exclusivo de mão-de-obra escravizada mudou pouco, deixando o trabalhador liberto e seus filhos em uma situação bastante frágil, na dependência do consentimento do proprietário da terra, geralmente seu empregador, para ocupar e utilizar um espaço limitado.

Este artigo concentra-se na análise da sociedade barbadiana no período do PósAbolição. Barbados era então uma colônia britânica cuja economia se baseava na monocultura da cana-de-açúcar e na utilização em larga escala de mão de obra de origem africana, descendentes de escravos. Por sua limitada extensão territorial e manutenção da composição social - tendo recebido um número limitado de imigrantes no período - a ilha pode ser utilizada como excelente estudo de caso para as tensões entre patrões/proprietários e empregados/inquilinos na luta pelo direito à moradia e ao acesso à propriedade privada. Um objetivo secundário é apresentar o leitor brasileiro a uma outra historiografia sobre o PósAbolição, produzida sobretudo por autores barbadianos, de forma a ampliar o leque das referências para os estudos da diáspora africana nas Américas.

O caso de Barbados, com suas especificidades, está inserido nas dinâmicas da Diáspora Africana nas Américas e na luta abolicionista, que nas colônias Britânicas foi vitoriosa em

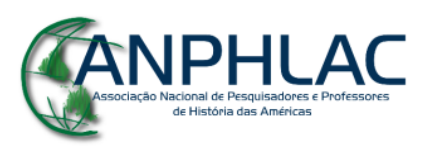


1834. O processo de integração dos afrodescendentes na sociedade de classes foi, porém, um processo longo que se arrastou até a segunda metade do século XX, quando negros de vários países alcançaram melhores condições de vida.

O período considerado Pós-Abolição varia de um país a outro, resultado de abordagens metodológicas que buscam estabelecer limites de periodização entre os estudos da escravidão, dos efeitos da abolição da escravidão e das lutas por direitos para os libertos e seus descendentes (FORTES e MATTOS, 2015). Nos Estados Unidos, por exemplo, a periodização adotada para os estudos da história dos afro-americanos após o fim da escravidão não se sintetiza no monobloco do Pós-Abolição, dividindo-se em Reconstrução, Jim Crow Era e Luta por Direitos Civis (FONER, 2014; WOODVARD, 2002). ${ }^{2}$

A adoção de tal periodização visa ressaltar períodos críticos dessa história que não podem ser simplesmente reduzidos sob o conceito histórico da pós-abolição, como se estabeleceu no Brasil, ou no conceito do post-emancipation, conforme adotado no Caribe anglo-fônico. No caso do último, a política inglesa de estabelecer o Aprenticeship, o qual será discutido nas próximas linhas, criou um período que, ainda que curto, marcaria a experiência dos escravizados, merecendo ser tratado como um momento específico, ainda que no contexto do que se chamou post-emancipation.

A ausência de uma definição acadêmica de tal conceito e de sua extensão temporal, seja em português ou inglês, aponta para a fragilidade de tal temporalidade, uma vez que está muito claro o início de tal período, determinado pela assinatura de uma lei, mas não foram estabelecidos os parâmetros para o corte final, já que problemas ligados à discriminação e alienação dos descendentes de escravos e suas consequências continuaram a desafiar a

\footnotetext{
${ }^{2}$ Essencial para entender a luta por uma História dos negros nos Estados Unidos da América é o livro de John Hope Franklin: From Slavery to Freedom: a history of African Americans, publicado pela primeira vez em 1947 , período em que a disciplina se estabelecia no meio acadêmico, o livro foi revisado e atualizado duas vezes, em 1999, com a participação de Alfred Moss Jr. e em 2010 - após a morte de Franklin - com a participação de Evelyn Higginbotham. O livro, e suas duas reedições revisadas, abordam primeiramente da luta afro-americana pelo direito à história, acrescentando a luta dos anos pós-guerra até a era Reagan e, na última edição, se estende até a eleição do primeiro presidente negro naquele país.
}

\section{CANPHLAC}

Revista Eletrônica da ANPHLAC, ISSN 1679-1061, № 27, p. 37-65, Ago./Dez., 2019.

http://revista.anphlac.org.br 
sociedade barbadiana, por exemplo, por grande parte do século XX, com variados graus de intensidade.

A historiografia sobre os negros nas Américas tende a concordar que reformas sociais e políticas tenham começado a tomar corpo em várias sociedades a partir do final dos anos 1930, quando políticas sociais, tais como os projetos de moradia e de escola pública, saúde, adoção de legislação trabalhista e programas de combate à pobreza, passaram a oferecer algumas garantias aos trabalhadores, afetando positivamente a população negra em sua luta por trabalho, moradia, educação e dignidade.

Em geral, nos países onde a escravidão fora o alicerce da economia colonial a erradicação do trabalho escravo atendeu primordialmente às necessidades da oligarquia, procurando minimizar as perdas dos proprietários e, a partir de então, dos empregadores. Ainda que isso possa ser verificado nas pesquisas sobre o trabalho urbano de vários países, com a permanência do trabalho doméstico como último vestígio de exploração maximizada da mãode-obra, é no meio rural que se percebe a luta - às vezes silenciosa, noutras em confrontos abertos - pelo direito à liberdade, à propriedade e ao trabalho.

O problema da moradia e do acesso à propriedade pelo trabalhador livre no decorrer das décadas posteriores à abolição marcou várias sociedades e tem sido tema de estudos dedicados a examinar a integração social da população negra em vários países. Eric Foner se refere ao desapontamento dos negros libertos nos Estados Unidos da América que permaneceram trabalhando nas fazendas como meeiros ou jornaleiros, submetendo-se a condições de trabalho que os mantinham em situação de penúria e dependência. Nas cidades, se confrontaram com a oferta limitada de trabalho, os salários ínfimos que os patrões estavam dispostos a pagar pelo trabalho e a impossibilidade de encontrar moradia adequada. (FONER, 2014). Tais problemas se iniciaram imediatamente após a abolição, na chamada Reconstrução, se estendendo por todo o período do Jim Crow (PACKARD, 2003), chegando mesmo à atualidade.

George Andrews examinou a luta dos negros na Colômbia, Panamá, Peru, México, Equador, Argentina e Brasil, apontando para a adoção de leis contra a vadiagem, bem como de estatutos e normas para a promoção da "ordem pública", que restringiram a liberdade, limitaram as chances de negociação das condições de trabalho e de acesso à moradia. Não

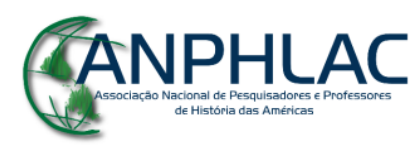

Revista Eletrônica da ANPHLAC, ISSN 1679-1061, № 27, p. 37-65, Ago./Dez., 2019.

http://revista.anphlac.org.br 
desconsiderando a luta secular que se trava pelo direito à terra por todo o continente, em países que tinham território mais amplo, como o Brasil, a Venezuela, a Colômbia e o Peru, a abundância de terras ofereceu aos camponeses maiores possibilidades de negociação no arrendamento das terras ou mesmo na ocupação de terras devolutas (ANDREWS, 2004).

No Brasil, o acesso a terras devolutas - ainda que fossem abundantes - também foi limitado pela legislação, quando a Lei de Terras de 1850 atendeu às preocupações da oligarquia em limitar o acesso dos trabalhadores à propriedade, impor o registro da propriedade por meio de documento de compra, ainda que o governo imperial e depois o republicano tenham concedido largas extensões de terras a seus aliados, e posteriormente ao estabelecimento de colônias de imigrantes estrangeiros. Mesmo assim, muitos libertos e camponeses pobres ocuparam terras devolutas, frequentemente desenvolvendo grandes comunidades, como no caso de Canudos ou do Contestado. As comunidades de posseiros eram sempre fragilizadas pela iminente possibilidade de que tais terras fossem reclamadas por algum proprietário ou autoridade política.

A decadência do regime escravista levou à elaboração de novas estratégias de controle da mão-de-obra para garantir sua viabilidade e diminuir os gastos com pagamentos por trabalho. As historiografias brasileira e estadunidense se referem ao controle do trabalhador por meio do sistema de armazéns que leva ao endividamento e manutenção da dependência, não omitindo os casos de abusos físicos e humilhações de trabalhadores. Tais abusos se apoiavam em um sistema político-social de privilégios, no qual indivíduos eram discriminados pela cor da pele e posição social.

Em grande parte do continente e nas ilhas-Estado do arquipélago caribenho, a economia de exportação fundamentada na grande propriedade agricultora prevaleceu até boa parte do século XX, quando alguns países passaram a diversificar suas economias, dando lugar a outras formas de relações trabalhistas. No Pós-Abolição, o recém-liberto dependia do ex-senhor para obter ferramentas, alimentação, vestuário, moradia e socialização (igreja, escola, espaço de lazer, etc.), em um sistema que é considerado como uma extensão da escravatura, devido ao grande controle que o empregador tinha sobre os empregados. Nessas condições, a capacidade desses trabalhadores de negociar melhores arranjos de trabalho e salários era limitada pela necessidade de um espaço para viver.

\section{GANPHLAC}


Tal controle sobre o trabalhador foi ainda mais evidenciado em países de dimensões territoriais limitadas, como no Caribe. Na República Dominicana, por exemplo, onde o latifúndio açucareiro se desenvolveu tardiamente, a necessidade de mão-de-obra acessível e de baixo custo levou o governo local, em acordo com investidores dos Estados Unidos ao final do século XIX, a alterar o regime de ocupação de terras, afetando principalmente as propriedades comunales, que foram reduzidas ou eliminadas, em benefício do latifúndio. Enquanto isso, os ejidos (propriedades governamentais que eram arrendadas a pequenos agricultores) foram também reduzindo os contratos de arrendamento, obrigando assim os camponeses que gozavam de independência a se empregarem nas grandes fazendas ou engenhos (BRYAN, 2018).

Higman aponta para o fato de que mesmo que as ilhas do arquipélago sejam sociedades diferenciadas, há elementos em comum, tais como a limitação territorial e a densidade populacional nas ilhas, incluindo a predominância dos trabalhadores negros, ex-escravos, dominados por uma oligarquia branca. Nas colônias britânicas, ainda antes da abolição, as negociações sobre as condições de trabalho entre senhores e escravos levaram a um arranjo em que o trabalhador escravizado tinha o direito de plantar hortaliças e vegetais em pequenos retalhos de terra, cujos frutos poderiam ser consumidos pela família escrava ou ser negociados no mercado local aos finais de semana. Com o fim do sistema de trabalho escravo, os senhores passaram a pagar um salário considerado irrisório aos trabalhadores e cobrar o aluguel pela moradia e pelo uso da terra. A princípio, muitos trabalhadores não abandonaram as fazendas devido a laços de camaradagem e parentesco, mas também para não abandonarem suas pequenas roças (HIGMAN, 2011).

Segundo o mesmo historiador, tão importante quanto considerações econômicas na busca de soluções para a moradia de trabalhadores são aquelas sobre laços sociais e familiares. Em outras palavras, a escolha sobre onde morar, ou sobre ficar ou partir, está também ligada ao grupo familiar e social no qual o trabalhador está inserido. Consequentemente, o êxodo das fazendas em direção às cidades ou a outras regiões não foi um processo imediato ou rápido, mas se construiu com certa lentidão, cheio de idas e vindas, tentativas e fracassos, na busca de um lugar para estabelecer um lar para a família. Dado verificado por Kim Butler (1998) e Carlos Eduardo Costa (2013) em seus estudos sobre o período Pós-Abolição no Brasil; na análise de

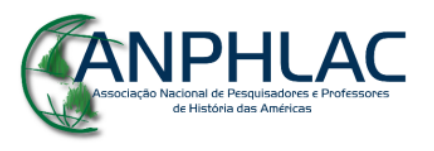


Eric Foner sobre o período da Reconstrução (2015) e Isabel Wilkerson sobre a era de Jim Crow até a luta pelos direitos civis (2010) nos Estados Unidos; e nosescritos de Erna Brodber (2004) e Olive Senior (2014) sobre as emigrações do Caribe Inglês.

Sem dúvida, se a experiência da escravidão faz parte de um dos mais traumáticos momentos da história humana, a abolição do trabalho escravo, da forma como se deu, deixou milhões de pessoas em estado crítico de abandono. Em várias partes das Américas, homens, mulheres e crianças negras se viram desamparados em todos os sentidos, negados o direito de propriedade e pagamento justo por seu trabalho. As classes senhoriais também criaram leis que coagiam as pessoas ao trabalho, bem como um sistema de policiamento que coibia as migrações internas ao exigir dos trabalhadores passes assinados por seus empregadores, permitindo-lhes o trânsito pelas estradas e apreendendo supostos vagabundos para submetê-los ao trabalho compulsório nas fazendas ou em obras públicas. As leis contra a vadiagem surgiram durante o declínio da escravidão em diferentes sociedades com o objetivo de coagir pessoas livres a trabalharem, limitando-lhes o poder de barganha sobre o valor de sua mão-de-obra e as condições de trabalho.

O testemunho de Merrimon Howard, ex-escravo do estado de Mississipi, na comissão que apurava ações de impedimento ao eleitor negro naquele estado, em 1876, revela a situação dos negros após a abolição da escravidão nos Estados Unidos, e também reflete as políticas do Brasil e do Caribe inglês quanto ao tipo de apoio dado ao ex-escravo:

...Todo homem e mulher deveriam possuir tanto quanto eles possam trabalhar. Porém, negros foram deixados sem terra, sem casa, nem ao menos um lugar para descansar suas cabeças... Desprezados pelo mundo, odiados no país que os viu nascer, negados de todos os direitos como pessoas, nós éramos amigos na marcha, irmãos nos campos de batalha, mas na busca pacífica de uma vida melhor, parece que somos estranhos. (FONER, 2014, p. 74). ${ }^{3}$

O caso do Caribe inglês, porém, traz algumas diferenças. Em primeiro lugar, eram colônias com território limitado, algumas, como Antígua, com menos de $300 \mathrm{~km}^{2}$, outras, como St. Vincent \& Grenadines, eram compostas por várias pequenas ilhas, a maior delas com $26 \mathrm{~km}$

\footnotetext{
${ }^{3}$ Todas as traduções neste texto foram realizadas pela autora a partir da versão em inglês. Esse depoimento está disponível na íntegra na coleção de documentos digitalizados pela Freedmen and Southern Society Project. Disponível em: http://www.freedmen.umd.edu/LL66-67pg.html Acesso em 30/05/2019.
}

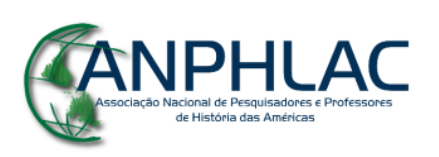


de comprimento por $15 \mathrm{~km}$ de largura. Em segundo lugar, o trabalho escravo foi decretado ilegal em 1834, durante um período em que a população dessas colônias era composta de uma ampla maioria de negros, com população branca abaixo de 10\%, distribuídos entre proprietários e uma limitada classe média constituída de funcionários públicos e alguns artesãos e mercadores. Finalmente, a abolição não alterou em nada o regime político das ilhas, que continuaram a ser colônias inglesas, negaram direitos políticos à população negra e mantinham normas de segregação racial.

Segundo Robert Schomburgk, que escreveu uma história de Barbados publicada pela primeira vez em 1848, a resistência da elite colonial ao projeto abolicionista levou a Coroa Britânica a estabelecer um período de "aprendizado", o apprenticeship, no qual o escravo liberto continuaria a trabalhar para seu senhor ou senhora em preparação para a liberdade plena. A legislação assinada em 1833 propunha que trabalhadores domésticos, empregados do comércio e artesãos deveriam servir como aprendizes por quatro anos, enquanto que aqueles que trabalhavam nos campos ou na produção de açúcar ou rum estenderiam o período de aprendizado por seis anos (SCHOMBURGK, 1848). A resistência dos trabalhadores em aceitar tal diferenciação e o risco de rebeliões levou o projeto a ser revisto e a completa abolição aconteceu em 1 de agosto de 1838. Segundo Higman,

(...) o período do Aprendizado durou de 1834 a 1838, com a intenção declarada de introduzir o ex-escravo a um novo sistema, no qual ele teria que negociar salários, pagar aluguel por moradia e terra, e cobrir suas despesas médicas. O povo aprendeu pouco e, de fato, havia pouco a aprender. O Aprendizado tinha mais que ensinar à classe senhorial. O sistema foi desenhado para ajudar os fazendeiros a fazer a transição para o trabalho livre atando pessoas supostamente livres às plantations... (HIGMAN 2011, p.157). ${ }^{4}$

\section{Pós-Abolição em Barbados}

A ilha de Barbados tem apenas $430 \mathrm{~km}^{2}$ (para se ter uma ideia, o estado do Rio de Janeiro tem quase $43.700 \mathrm{~km}^{2}$ ) e o número atual de habitantes é aproximadamente $280 \mathrm{mil}$, dos quais $90 \%$ são de origem africana. Em 1838, quase a totalidade das terras barbadianas estava

\footnotetext{
4 Tradução da autora.
}

\section{CANPHLAC}


ocupada pelas fazendas de cana de açúcar, com exceção dos poucos e diminutos núcleos urbanos que se formaram em torno das igrejas e, no caso de Bridgetown e Speightstown, em torno dos portos. O território, quase todo plano, não oferecia montanhas ou vales de difícil acesso nos quais escravos fugidos pudessem se esconder, nem rios ou lagos. No Pós-Abolição, não havia terras devolutas que pudessem ser ocupadas em Barbados. Quando a lei que decretava a liberdade foi assinada, havia na ilha 489 plantations, que ocupavam quase $85 \%$ do território e eram propriedade de 625 pessoas, dentre as quais apenas três não eram brancas. (BELLE, 1996).

Leis de prevenção e punição à vadiagem foram criadas enquanto se legislava sobre a abolição. Alguns dias antes do início do período de aprendizado, em 29 de julho de 1834, o governo colonial autorizou a organização de uma força policial rural e o estabelecimento de uma estação de polícia em Bridgetown, "para facilitar o controle dos trabalhadores aprendizes e garantir e reforçar a reciprocidade de deveres entre trabalhadores e patrões" (SCHOMBURGK 1848, p. 461). Os casos de abusos da polícia rural e de pendências sobre cumprimento de contrato entre empregados e patrões deveriam ser julgados nas devidas paróquias, por juízes nomeados pelo governo local. Isso apesar da preocupação expressa da comissão encarregada de implementar o novo sistema, que temia que tal recurso pudesse levar à corrupção do processo, visto que a elite fundiária e todas as autoridades envolvidas tinham interesses em comum e opostos aos interesses dos trabalhadores (SCHOMBURGK 1848, p. 463).

$\mathrm{O}$ poder dos fazendeiros se estendia à política nos mais variados níveis, com exceção de alguns cargos nomeados pela administração colonial, que enviava altos funcionários diretamente da Inglaterra, a elite local detinha o controle do Parlamento, juízes, Câmara de Comércio, prisões, policiamento e até igrejas. De acordo com Hilary Beckles, havia em Barbados 83.150 escravos no ano de 1838, e o monopólio da propriedade de terras era essencial para manter o controle econômico, político e social. A elite, que tinha laços estreitos de parentesco com os grandes mercadores, contava com o apoio das autoridades coloniais que deveriam evitar a todo custo o estabelecimento de uma classe camponesa de pequenos proprietários independentes, como vinha acontecendo na Jamaica. Em outras palavras, as pessoas libertas deveriam estar completamente subordinadas e controladas mesmo que à força

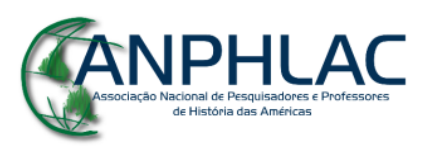


e alienadas do poder de barganha ao negociarem o uso de sua força de trabalho, de forma que a elite continuasse a obter lucros exorbitantes na exploração da economia (BECKLES 2004). O mesmo autor define os contratos de tenantry ${ }^{5}$ aos quais os trabalhadores estavam forçados como uma relação que reunia elementos de servidão e terror. Os melhores trabalhadores, mais fortes, hábeis e saudáveis, tinham prioridade nos contratos. Outros, em piores condições físicas ou habilidade para o trabalho, como os doentes, aleijados, velhos, mulheres e crianças eram incluídos em contratos menos favoráveis.

Os trabalhadores barbadianos podiam andar, e andavam, mas não havia espaço seguro na ilha para correr. Grande parte do sucesso da elite em estabelecer uma cultura (opressiva) de trabalho e de propriedade, pode ser resumida no fato desses trabalhadores poderem andar mas não poderem correr. (BECKLES, 2004, p. 49).

A predominância de mulheres entre os trabalhadores desde o início do sistema escravista é outro fator importante apontado por Beckles como elemento que deu aos empregadores maior vantagem tanto na compra da mulher escrava, que era sempre mais barata que o homem, quanto depois, como empregada, quando recebia salários abaixo daqueles pagos aos homens (BECKLES, 1999).

Baseando-se na leitura de jornais barbadianos da época, Laurence Brown e Tara Inniss apontaram para um número crescente de despejos de trabalhadores entre os anos de 1838 e 1839 em Barbados, e como afetaram a população feminina. Tais despejos eram executados pelo proprietário e administradores, e as autoridades raramente eram chamadas para intervir, o que mostra como a preocupação das autoridades coloniais sobre a justiça do sistema era real, e que a situação ficou ainda mais grave que o previsto inicialmente, pois os empregadores tendiam a levar os despejos a cabo independentemente. O jornal $O$ Liberal de 20 de março de 1839 ressaltava o caso de "Nanny Sue, jovem viúva que fora expulsa da fazenda onde havia nascido, vivido e trabalhado sua vida inteira, com uma criança de três anos e outra de três meses." $\mathrm{O}$

\footnotetext{
${ }^{5} \mathrm{~A}$ palavra "tenantry" se traduz para o inglês literalmente como "inquilinato", porém, considerando o contexto histórico no qual está sendo referida, tenantry representa muito mais que o relacionamento entre inquilino e proprietário, referindo-se a um sistema de exploração e de controle da mão-de-obra que floresceu com a abolição e continuou até a quarta década do século XX, em Barbados. Apesar de o sistema ter sido adotado em outras colônias inglesas, e ser possível encontrar sistemas semelhantes em outros lugares, o modelo barbadiano é considerado o mais perverso devido à limitação do território e, consequentemente, de opções de resistência.
}

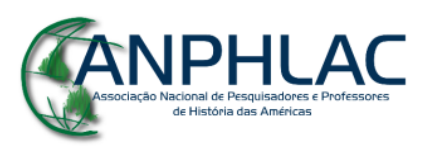

Revista Eletrônica da ANPHLAC, ISSN 1679-1061, № 27, p. 37-65, Ago./Dez., 2019.

http://revista.anphlac.org.br 
despejo foi motivado pelo fato de Nanny Sue estar doente e incapacitada para o trabalho. O patrão não levou em consideração o fato de que ela tinha construído sua choupana com seu marido, e além da moradia, a jovem perdeu o pedacinho de lote onde havia plantado batatas (BROWN \& INNISS 2008, p. 177).

Em 1838 foi assinado o Masters and Servants Act, também conhecido como Lei de Contrato de Trabalho, que atava os trabalhadores libertos às plantations em condições que beneficiavam unicamente aos patrões. Adultos e crianças poderiam ser presos por atos de insubordinação, por xingarem, praticarem jogos de azar, roubarem uma fruta ou uma cana para chupar. Atos de insubordinação incluíam a reunião de algumas pessoas comentando sobre injustiças no regime de trabalho ou pagamentos irrisórios (BECKLES, 2011). Crianças poderiam ser espancadas por inspetores se encontradas perambulando em áreas da cidade que eram predominantemente ocupadas por famílias brancas (BROWNE, 2012). Para os adultos, além da prisão, punições físicas com chicotadas eram comuns (SCHOMBURGK, 1848). Adicionalmente, foram criadas leis que proibiam a emigração dos trabalhadores e colocavam na prisão qualquer agente recrutador para trabalhadores em outros territórios (RICHARDSON, 1985).

Para Henderson Carter (2012), o Master and Servants Act, as leis contra a vadiagem, as leis contra emigração e a criação da Força Policial eram parte de um mecanismo maior para controlar o trabalhador e coibir qualquer iniciativa de rebelião ou mesmo resistência contra a ordem imposta pela oligarquia. Em 1838 foi aprovado pela Assembleia o "Ato para Prevenção de Tumultos e Assembleias Rebeldes, de acordo com tal ato, qualquer ajuntamento de 12 pessoas ou mais, que tenham ilegalmente, tumultuosamente ou em atitude rebelde se juntado para perturbar a paz pública, poderia ser dispersado. Pessoas que resistissem poderiam ser condenadas a até 3 anos de prisão" (CARTER, 2012, p.31).

Outra forma de pressionar trabalhadores e trabalhadoras a aceitarem contratos de trabalho em condições desfavoráveis era a existência de crianças menores de seis anos. Enquanto que a partir de seis anos, entendia-se que a criança negra já podia exercer funções de trabalho, os menores eram completamente dependentes, portanto, não geravam nenhum lucro ao empregador. Com os salários minguados e a redução da possibilidade de cultivo de pequenos lotes, agravados pelo constante risco de ser expulso e ter que procurar outro lugar para viver, alimentar as crianças se tornou um grande desafio. Beckles $(2004 ; 2006)$ demonstra que o

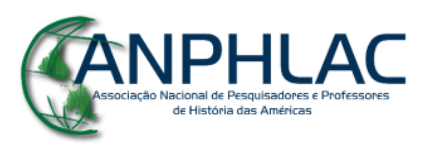

Revista Eletrônica da ANPHLAC, ISSN 1679-1061, № 27, p. 37-65, Ago./Dez., 2019.

http://revista.anphlac.org.br 
rendimento das grandes propriedades cresceu durante os anos imediatos à abolição. Seus dados mostram que a exportação de açúcar subiu de 17.234 toneladas em 1835 para 23.679 toneladas em 1838 em Barbados, um dos únicos lugares no Caribe Inglês onde tal fenômeno ocorreu. Ao mesmo tempo, a mortalidade infantil subiu assustadoramente, ao ponto de autoridades da Igreja Anglicana iniciarem uma campanha para alimentar as crianças, mesmo reconhecendo que isso não era uma maneira eficaz de lidar com o problema. Evidências angariadas pelo mesmo autor indicam que houve críticas de autoridades religiosas e de autoridades inglesas à excessiva exploração dos trabalhadores, porém tal criticismo não resultou em mudanças nas atitudes da classe senhorial de Barbados.

\section{Da escravidão à miséria}

A proposta de plena liberdade não se realizou durante os primeiros anos da abolição. A condição do trabalhador livre, ainda frágil, era desafiada por aqueles que eram contrários à ideia de elevar os negros à condição de trabalhadores assalariados. John Taylor foi condenado a 14 anos de prisão por haver tirado da ilha, no ano de 1836, "vários trabalhadores livres de cor e tê-los vendido como escravos no Texas", a acusação foi baseada em "evidências tão claras que não houve dúvidas de que ele tivesse (de fato) cometido tal crime" (SCHOMBURGK 1848, p. 489).

Carter (2012) se refere ao período entre 1838 e 1904 como a era da "expansão da pobreza", quando os trabalhadores se viram completamente destituídos de qualquer proteção a seus direitos mais básicos. Períodos de seca, queda no preço do açúcar no mercado internacional, tempestades e furacões, avanços tecnológicos na produção (como a implantação de engenhos a vapor) e epidemias de cólera, tifo, varíola e febre amarela tornavam a situação ainda mais aguda na segunda metade do século XIX. Quando a crise levava à falência da propriedade fundiária, as autoridades locais se encarregavam de avaliar imóveis e maquinário, promovendo a venda entre membros da elite, uma estratégia para evitar que as fazendas fossem desmembradas em pequenos lotes.

O preço do acre de terra cultivável no Caribe em 1848 girava entre 1 a 3 libras na Dominica, entre 4 e 20 libras na Jamaica e tinha em Barbados o custo mais alto: entre 6 e 120 libras por acre (BECKLES 2006, p. 153). Os salários, por sua vez, eram muito mais baixos em

\section{CANPHLAC}


Barbados entre 1846 e 1850. A média de pagamento por um dia de trabalho era de 6 pences em Barbados, enquanto na Jamaica se pagava 15 pences, na Guiana Inglesa o pagamento médio era de 20 pences, e em Trinidad 24 pences (BECKLES, 2006, p. 195).

Conforme depoimento de um magistrado recuperado por Careen Banton, dentre os documentos do Parlamento de Barbados para o ano de 1841,

\begin{abstract}
...pouco progresso tem sido feito pelos trabalhadores em se estabelecerem como pequenos proprietários, não por falta de inclinação para tal empreitada, mas as circunstâncias da nossa ilha acarretam uma possibilidade diminuta de um grande número (de trabalhadores) obterem alguma posse. (...) A razão é óbvia; não há na inteira ilha, um pedaço de terra devoluta que seja útil para cultivo, e sendo a ilha principalmente dividida entre plantations, os proprietários não parecem inclinados a vender pequenas porções de terra para tal propósito; e não há terras públicas disponíveis, consequentemente, pequenos proprietários não podem se estabelecer neste país (BANTON, 2011, p. 8)
\end{abstract}

Os salários pagos nas fazendas variavam de acordo com o tipo de trabalho executado, sendo que empregados que exerciam funções mais especializadas conseguiam um ganho um pouco acima daqueles que executavam serviços gerais no campo e nos engenhos. Barbados oferecia as piores condições de trabalho e pagamentos de todo o sistema colonial inglês caribenho. Mulheres que trabalhavam nos campos recebiam pelo menos $25 \%$ a menos que os homens, enquanto que as crianças a partir de 12 anos recebiam metade do pagamento médio de um adulto. $\mathrm{O}$ salário poderia ser ainda menor se considerando a capacidade física e a idade do trabalhador, colocando pessoas acima de 40 anos e abaixo de doze em condições ainda mais precárias. Como a moradia estava condicionada diretamente ao trabalho, o aluguel da casa ou do terreno estava embutido no salário. Em outros casos, a moradia era cedida como parte do acordo de trabalho. Porém, nesse caso, qualquer falta ao trabalho, mesmo que por motivo de doença ou condições relacionadas a gravidez ou parto, poderia acarretar na cobrança de aluguel pelos dias de ausência, resultando em diminuição dos ganhos e subsequente aumento de suas dívidas com o proprietário (Beckles, 2004; Carter, 2012; Browne, 2012).

O sistema de tenantry atingia as mulheres e crianças de forma mais aguda que os homens. Além de receberem pagamentos mais baixos, as mulheres tinham de cuidar das crianças, dos velhos e da pequena horta ou roça que tanto contribuía para o sustento das famílias. Para evitar a perda de suas moradias e pequenas roças, elas aceitavam piores condições de trabalho, enquanto os homens muitas vezes saíam de uma propriedade e

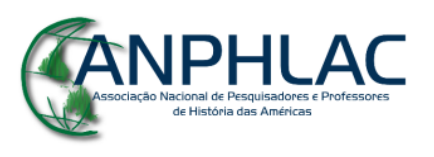


ofereciam sua força de trabalho em outras fazendas ou mesmo no porto. Alguns autores falam sobre a prevalência de abusos físicos e sexuais perpetrados contra mulheres e meninas, os quais contribuíam para aumentar a carga de mulheres que se viam obrigadas a sustentar filhos gerados em atos de violência sozinhas. Mulheres e meninas eram alvo dos abusos de patrões, capatazes, vizinhos e às vezes membros da própria família (INNISS, 2014; YATES, 1998; BECKLES, 2000). A maioria aceitava tais abusos como parte do peso de ser mulher, evitando reclamar para não arriscarem maiores perdas.

Ainda que sob extrema pressão dos fazendeiros, alguns homens e mulheres conseguiam combinar suas atividades nas fazendas com a pesca, trabalho artesanal como carpintaria e a manutenção de pequenas roças cultivadas em pedaços muito pequenos de terrenos, a partir dos quais produziam alguma mandioca, batata-doce, abóbora, feijão guandu ou mesmo cana-deaçúcar. Alguns, com mais sorte, viviam em terrenos com árvores frutíferas como mangas, goiabas ou fruta-pão. Essas pessoas levavam o fruto de seu trabalho ao mercado local, onde vendiam ou trocavam produtos. Woodville Marshall (1996) relaciona essa iniciativa ao nascimento de uma classe de pequenos agricultores empreendedores, que depois se tornaram pequenos comerciantes. Para alguns, tal ganho representou a possibilidade da compra de uma passagem em um barco que os levaria a outras colônias, onde poderiam conseguir salários mais altos ou mesmo a oportunidade de adquirir um pequeno pedaço de terra. Pessoas começaram a emigrar de Barbados desde os anos 1840 em direção à Guiana Inglesa, onde a economia de plantations começava a florescer, ou para colônias espanholas como Cuba e Porto Rico. (MARSHALL, 1996; THOMAS-HOPE, 2009; ROCHA e ALLEYNE, 2012).

Em geral, o trabalhador emigrado mantinha laços familiares e afetivos em Barbados. De fato, provar que tinha tais laços e dependentes era a condição para conseguir permissão e os documentos necessários para emigrar oficialmente. Ainda que muitos tenham partido sem obterem os documentos legais, o compromisso em ajudar os que ficaram para trás era parte de uma espécie de lei moral, a qual a maioria buscava respeitar. O dinheiro das chamadas remitências, enviadas via serviço postal, era aplicado na compra de um lote de terra e a educação das crianças (ROCHA e ALLEYNE, 2012; NEWTON, 2004).

\section{CANPHLAC}




\title{
Condições de moradia no Pós-Abolição
}

A Comissão Executiva da Sociedade Americana Anti-Escravidão recebeu com grande entusiasmo a notícia da abolição nas colônias inglesas do Caribe, enviando dois de seus membros para uma viagem de reconhecimento às ilhas de Antígua, Barbados e Jamaica em 1837 com a missão de relatar o estado da economia e sociedade durante o período do aprendizado. ${ }^{6}$ A chegada dos americanos a Barbados foi assim retratada no relatório:

\begin{abstract}
Ao nos aproximarmos de Barbados, fomos apresentados a uma paisagem completamente diferente das outras ilhas que passamos no caminho. É baixa e plana, quase totalmente destituída de árvores e muito pequena. Mas ao nos aproximarmos, descobrimos em todas as direções as marcas do extraordinário cultivo. Os campos de cana, alternados por roças de alimentos de subsistência cobrem a ilha formando um manto verde sem fim. As mansões dos fazendeiros e as aglomerações de casas de negros aparecem a cada intervalo, pontuando a superfície da ilha... ${ }^{7}$
\end{abstract}

Thome e Kimball (1838) descreveram as "cabanas de negros" como construções precárias, feitas de uma mistura de paus e o que parecia ser bambus (eles chamam de cana) entrelaçados para fazer a parede e em partes rebocadas com barro. A cobertura dessas cabanas era feita de palha ou algum tipo de capim. Essas casas eram construídas pelos próprios negros usando material recolhido na área em que viviam. O mesmo relatório fala sobre o grande aumento no custo das terras, citando o testemunho de um grande proprietário, que também afirmava ter reduzido seus gastos na administração da fazenda já no primeiro ano do aprendizado. Em outras palavras, o aumento dos lucros dos proprietários estava ligado à extrema exploração dos trabalhadores.

A partir de 1840, alguns fazendeiros cederam lotes para a implantação de vilas para acomodar empregados e suas famílias, outros cediam pequenos lotes, nos quais o trabalhador tinha a permissão para construir uma cabana para viver. Estas, porém, eram condições vulneráveis, pois a moradia era garantida enquanto o trabalhador se mantivesse ligado à

\footnotetext{
${ }^{6} \mathrm{O}$ longo relatório de Jas. Thome e Horace Kimball foi publicado pela mesma sociedade, em 1838, e contribuiu para a construção do argumento em favor do trabalho livre nos Estados Unidos. A partir de 1839, o jornal Barbados Mercury publicou partes do relatório que eram relacionadas àquela colônia. Uma leitura cuidadosa do relatório é necessária, considerando que a maioria das informações coletadas foi oferecida pelos proprietários e autoridades, que também foram os guias dos visitantes em cada ilha.

7 "Emancipation in the West Indies. A six months tour in Antigua, Barbados and Jamaica by Jas. A. Thome and Horace Kimball”, Barbados Mercure, 02/02/1839, p. 3.
}

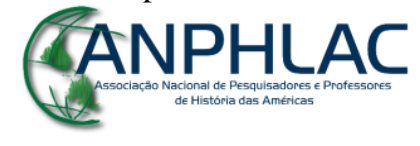


propriedade. A cada crise, os empregadores dispensavam trabalhadores, que, por sua vez, eram obrigados a buscar outro lugar para viver. O desemprego estava sempre ligado ao desabrigo de famílias trabalhadoras. Nessas condições, a população negra desenvolveu uma técnica de construção de moradia móvel, pequenas moradias muito leves, feitas de madeira ou de qualquer material existente, que podiam ser removidas de um lugar para o outro em cima de uma carroça. Eram as chamadas chattel houses (HIGMAN, 2011).

$\mathrm{O}$ alto índice de mortalidade infantil nas décadas posteriores à emancipação, que chegou a ser muito maior que durante o período da escravidão, atesta o abandono e a negligência em que as famílias se encontraram quando se tornaram trabalhadores livres. Apurou-se que não ocorrera epidemia que pudesse causar as mortes, pelo que foi estabelecido que as causas estavam relacionadas ao abandono de tais crianças pelos pais e pela falta de alimentação adequada. Dessa forma, recaía sobre os pais, e principalmente sobre a mãe, a culpa pela morte dos filhos, quando não podiam dar alimentação ou cuidar adequadamente de sua prole (BECKLES, 2004; BROWN \& INNISS, 2008; SCHOMBURGK, 1848).

Para as autoridades, o problema social era causado principalmente por uma crise moral, que deveria ser resolvida por meio da adoção da família nuclear, na qual o homem é o provedor. Sidney Greenfield (2010) ressalta que apesar das autoridades desse período incentivarem os trabalhadores ao casamento oficializado em vez do estabelecimento de uniões instáveis ou fora dos registros oficiais, os baixos salários pagos aos trabalhadores e as condições de trabalho não favoreciam a formação de famílias. Além do custo do casamento em si, a possibilidade de estabelecer uma casa familiar nem sempre era realizável, já que os homens tendiam a mudar de emprego na busca por melhores condições de trabalho, eventualmente chegando a emigrar, e mesmo que morando em Barbados, as dificuldades de locomoção entre fazendas dificultavam tais arranjos.

Em 1839, duas trabalhadoras irmãs apareceram na Corte de Apelos de Barbados por conta de terem sido expulsas da fazenda onde trabalhavam. O caso se deu quando uma das irmãs, Queen, se ausentou da fazenda por três semanas, quando esteve visitando seu marido em outra fazenda, um tanto distante de onde vivia. Segundo ela, sua prolongada ausência se deu por conta de uma doença. Durante sua ausência, a casa onde vivia com Molly, a outra irmã, foi várias vezes revistada por um funcionário administrativo da fazenda, que acusava Molly de

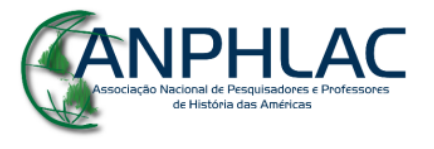

Revista Eletrônica da ANPHLAC, ISSN 1679-1061, № 27, p. 37-65, Ago./Dez., 2019.

http://revista.anphlac.org.br 
estar escondendo a irmã, que se recusava a trabalhar. Ao retornar à fazenda, Queen e sua criança foram expulsas da casa de Molly, que por sorte não perdeu seu emprego e moradia. Muitas vezes, ao abrigar um familiar expulso da fazenda em sua casa, o trabalhador e sua família perdiam o direito de moradia (BROWN e INNISS 2008). Essa era uma forma de fazer com que a família pressionasse o indivíduo para que não quebrasse as regras da fazenda, evitando que todo o grupo familiar fosse punido, conforme no caso de Betsy.

Betsy Cleaver trabalhava sob contrato na fazenda Neale. Como parte do seu contrato, ela alugava meio acre de terra (aproximadamente $2 \mathrm{mil} \mathrm{m}^{2}$ ) pertencente ao patrão, no qual plantava cana de açúcar, que vendia. Também como parte do contrato ocupava uma moradia que consistia de uma cabana, coberta com palha ou material semelhante. O marido de Betsy trabalhava na fazenda vizinha. Na época da colheita, o administrador da propriedade insistiu para que a colheita da fazenda fosse realizando primeiramente, sendo que somente após sua finalização, Betsy poderia cortar sua própria cana. Betsy argumentou que a demora afetaria a sua colheita e iniciou arranjos para que seu marido pudesse ser liberado de seus afazeres na fazenda vizinha para que juntos pudessem cuidar de sua roça. Irritado com a insubordinação, o administrador ordenou que a casa de Betsy fosse descoberta - retirada a palha que cobria - e que suas coisas fossem atiradas na estrada. Quando Betsy buscou refúgio na casa de seu tio, o administrador ordenou que também a casa de seu tio fosse descoberta, o que foi feito durante a noite, enquanto o velho dormia. $\mathrm{O}$ caso foi levado à corte de apelação, na qual, diante do magistrado, o administrador admitiu o feito, dizendo que era a punição por aquela mulher ter desobedecido suas ordens. Ele ainda defendeu que se o mesmo fosse feito em cada fazenda, diminuiriam os casos de desobediência aos patrões (BECKLES, 2004 p.88-9).

Tais eventos ocorridos em Barbados podem ser comparados a casos semelhantes registrados por historiadores brasileiros, como o ocorrido narrado por Cornélio Cansino a Ana Lugão Rios em Memórias do Cativeiro, no qual ele conta que seu avô tinha uma roça bonita plantada no terreno arrendado do patrão, para quem ele continuava a trabalhar como meeiro após a abolição. Segundo Cornélio, seu pai deixou de ir trabalhar no cafezal do patrão um dia, pois tinha de "capinar" sua rocinha,

“- Aí o fazendeiro mandou tirar a cerca e botou os bois dele tudo pra comer! (...) O fazendeiro botou os bois dele pra comer tudinho, dizendo que ninguém vai ficar rico

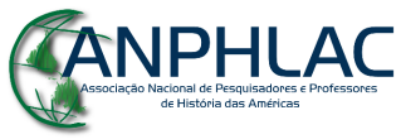

Revista Eletrônica da ANPHLAC, ISSN 1679-1061, № 27, p. 37-65, Ago./Dez., 2019.

http://revista.anphlac.org.br 
no terreno dele não. (...) Aí o meu tio pegou e levou nós tudo cá pra São José. Nóis fomos assim, cada um pegou um trapo e saímos, sabe por que? Porque não tinha nada, não. Era tudo tralha!"8

Além da pressão econômica sobre os trabalhadores rurais, a vida nas fazendas era considerada muito mais opressiva por causa das relações raciais e do controle que os proprietários exerciam sobre a mão-de-obra, configurando uma extensão das relações escravistas. Pouco a pouco, trabalhadores passaram a optar por abandonar a vida no campo e se mudarem para as cidades, onde, apesar da miséria e dos riscos de segurança e para a saúde, poderiam gozar de maior liberdade.

\section{Crescimento urbano}

Desde o século XVIII, a cidade de Bridgetown, e mais especificamente a área em torno do porto, atraía um comércio constituído de casas de prostituição, tabernas, casas de pensão, armazéns e vendas em geral. Tais lugares eram frequentados por pretos livres e de aluguel, bem como marinheiros e pessoas envolvidas com as atividades do porto. Após a abolição, a região atraía pessoas que tentavam sobreviver fora das plantações e do trabalho doméstico. Lavadeiras e vendedoras de comidas ou bebidas ocupavam lugares públicos, assim como homens que se ofereciam para qualquer serviço em troca de algum dinheiro.

Beckles (2004) se refere a uma preocupação das autoridades em relação à aglomeração urbana que se desenvolve em torno de Bridgetown, já em 1838, relacionando-a aos slums. Isso significa que mesmo com as leis punitivas, parte da população foi aos poucos se locomovendo para Bridgetown após a abolição, onde uma nova cultura se forjava.

Em diferentes partes da ilha, entre 1842 e 1890, começaram a surgir núcleos de povoamento, as chamadas free villages. Tais vilas tinham sua origem em um pedaço de terreno que era dividido em pequenos lotes, os quais eram vendidos aos trabalhadores em prestações a longo prazo. Os moradores de tais vilas eram, em sua maioria, trabalhadores das fazendas, e

\footnotetext{
${ }^{8}$ Trecho do filme documentário: Memórias do Cativeiro. Família, Trabalho, Cidadania no Pós-Abolição. Hebe Mattos (coordenação e roteiro), LABHOI/UFF, 2004.
}

\section{CANPHLAC}


devido à pobreza geral, os pagamentos poderiam se estender por até três gerações. (GREENFIELD, 2010).

Apesar do controle acirrado que a oligarquia exercia sobre os trabalhadores, crises circunstanciais, tais como seca, tempestades, morte do proprietário, queda de preço do açúcar no mercado externo, poderiam ter como consequências a falência da propriedade ou mesmo um problema financeiro que obrigasse a diminuição da produção. Nesses casos, trabalhadores perdiam empregos e moradias, saindo em busca de trabalho temporário nas fazendas, na cidade ou no porto. A cidade de Bridgetown começava a inchar.

Em 1871, Barbados tinha uma população de um pouco mais de 162 mil habitantes, dos quais 21 mil viviam em Bridgetown. Os registros oficiais falam de moradias amontoadas, casebres que tinham em média de $3 \mathrm{~m}$ por $3,5 \mathrm{~m}$, nos quais viviam até 10 pessoas. Com a aglomeração veio a promiscuidade e a contaminação. Ainda em 1871, a mortalidade infantil chegou a $23 \%$ na cidade (CARTER, 2008).

Nesse ambiente de extrema pobreza, desnutrição e condições de higiene bastante precárias, as epidemias tornavam a situação ainda mais grave. Em 1854, uma epidemia de cólera matou aproximadamente $20 \%$ da população da ilha em apenas três meses, afetando principalmente os moradores de Bridgetown e seus arredores. Secas, furacões, tempestades e doenças contagiosas contribuíam para abreviar a vida dos pobres, e muitas vezes dos ricos, na cidade.

Se o movimento do porto oferecia uma opção para os que haviam sido expulsos das plantations, as precárias condições sanitárias do centro urbano - sem água corrente ou sistema de esgoto - a aglomeração das casas e a promiscuidade em que viviam os moradores facilitaram a transmissão de doenças, a propagação de ratos e insetos, da violência física e sexual e dos abusos contra menores e mulheres.

Assim como nas fazendas, o preço dos aluguéis na cidade também era alto, e como no restante do país, não havia terrenos devolutos. O morador tinha a opção de pagar somente o aluguel do lote no qual colocaria sua casa, ou pagar aluguel pelo terreno e pela casa. Algumas mulheres conseguiam emprego como domésticas e com isso tinham a vantagem de dormir e comer no local de trabalho, porém, a maioria não podia trazer seus filhos consigo, deixando-os aos cuidados de algum parente ou com uma cuidadora de aluguel. A ausência de leis que

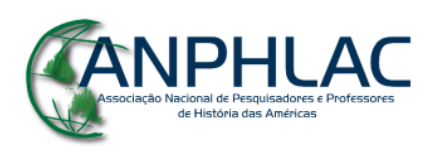

Revista Eletrônica da ANPHLAC, ISSN 1679-1061, № 27, p. 37-65, Ago./Dez., 2019.

http://revista.anphlac.org.br 
regulassem o trabalho doméstico colocava as empregadas em condições de trabalho que excediam 10 horas por dia, não previam o descanso semanal e nem regulavam salários.

Famílias extensas vivendo na mesma casa era algo comum, assim como era comum que mães saíssem para trabalhar deixando crianças sozinhas em casa. O trabalho infantil também era corriqueiro, assim como o furto para aliviar a fome. Já na virada do século XX, David Browne se refere a casos em que crianças entre 8 e 13 de idade que foram condenadas a receber chibatas por roubarem uma ou duas frutas, uma pequena quantidade de carvão ou três espigas de milho (BROWNE, 2008).

Carter aponta para mudanças estruturais nas moradias a partir de meados do século XIX. Segundo ele, a insegurança do lugar de moradia levou o trabalhador a alterar as técnicas de construção, adotando a madeira para as paredes e palha ou folhas de zinco para o teto, dependendo do poder aquisitivo da/o proprietária/o, com chão de terra batida. Dessa forma, as casas poderiam ser facilmente removíveis em caso de mudança. A partir de 1870, houve uma alteração no tamanho, quando as novas casas passaram a ter por volta de $3 \mathrm{~m}$ x $6 \mathrm{~m}$, consistindo de um cômodo divido em dois compartimentos, uma área comum e o quarto de dormir. Algumas famílias privilegiadas estenderam os fundos de suas casas com uma pequena cobertura, onde uma cozinha externa seria improvisada. Apesar desse progresso, ainda era comum, na virada do século XX, encontrar famílias extensas dormindo em espaços muito reduzidos (CARTER, 2012).

\section{Partir em busca de um lugar}

Além do fato de haver uma forte conexão entre as ilhas britânicas, as West Indies, como parte do poderio colonial inglês, havia grande circulação entre as ilhas de soldados, mercadorias, marinheiros. Os negros em Barbados sabiam que viviam em condições piores que seus vizinhos, sabiam que outras colônias ofereciam melhores salários. A possibilidade de emigração começava a se apresentar, principalmente para a Guiana Inglesa, que a partir de 1830 apresentou significante crescimento econômico. Em comparação à pequena ilha de Barbados, a Guiana Inglesa era bastante atrativa, com abundância de terras públicas e oportunidades para trabalho e empreendimento fora do sistema de plantations. Porém, Barbados estabeleceu leis

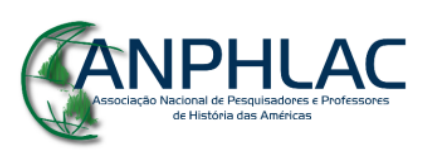


contra emigração, ao mesmo tempo em que criou as leis contra vadiagem, para evitar o êxodo do trabalhador barbadiano e obrigá-los à submissão, como se pode verificar no caso de Jane Dayrell.

Em abril de 1840, o magistrado de Bridgetown convocou Jane Dayrell, uma pobre viúva, a responder à acusação de incitar a emigração. A base da acusação foi o fato de que uma autoridade daquele tribunal, passando pelo caminho do mercado, ouviu quando a viúva discutia com o vendedor de lenha que queria cobrar um preço que ela considerava exorbitante. Em meio à discussão entre o vendedor (negro) e a viúva (branca), o homem teria dito a ela que precisava de dinheiro para viver, ao que ela teria respondido que se ele achava que sua vida era injusta em Barbados, porque então não emigrava para Demerara (Guiana Inglesa), “onde poderia ter uma vida melhor?" Essa teria sido uma conversa sem consequências, não fosse o testemunho da autoridade, que autuou a senhora imediatamente, baseando-se no "Emigration $A c t$ ", lei que determinava que qualquer pessoa que promovesse a emigração de Barbados seria processada e poderia ser presa. A defesa alegou não haver evidência de intenção por parte da viúva e com isso Jane foi absolvida (BANTON, 2011).

A lei contra emigração e os vários atos no mesmo sentido que vieram depois não conseguiram conter a evasão de trabalhadores do campo que conseguiam, via contrabandistas, partir para a Guiana ou para Trinidad. Menos de dez anos depois da abolição, o movimento migratório era notado por parlamentares e autoridades. A grande maioria dos emigrantes era composta de homens, o que deixava as mulheres em condições ainda piores, lembrando que elas substituíam os homens nos campos de cana, aceitando contratos de trabalho muito piores que seus companheiros (BECKLES, 2006).

A década de 1860 marca o início dos contratos entre trabalhadores negros de Barbados e a American Colonization Society, dedicada à colonização da costa ocidental da África. Ao aceitarem embarcar no projeto americano de colonização da Libéria, esses trabalhadores expressaram desejo de se estabelecerem em um lugar onde pudessem alcançar melhores condições de vida por meio de seu esforço e trabalho (BANTON, 2019). A promessa de uma vida melhor na Libéria era ainda mais atrativa em períodos em que a crise econômica se acirrava.

\section{CANPHLAC}

Revista Eletrônica da ANPHLAC, ISSN 1679-1061, № 27, p. 37-65, Ago./Dez., 2019.

http://revista.anphlac.org.br 
O ano de 1863 foi particularmente difícil para a população negra de Barbados. A seca afetou negativamente as plantações de cana-de-açúcar e, para diminuir as perdas, os proprietários cortaram os gastos com mão-de-obra. Em consequência, a fome se alastrou e com ela as doenças e a desordem. Incêndios apareceram por toda parte, negros acusados de atear fogo às plantações em vingança pela opressão sofrida, adultos e crianças detidos por furto (batatas, milho, cana, etc.). Carter se refere a mais de três mil pessoas presas por furtos entre 1862 e1863 (CARTER, 2012).

Entre 1860 e 1880, as crises econômicas e as tensões políticas se ampliaram em Barbados, com inúmeras rebeliões e saques a campos de batatas por hordas de trabalhadores e crianças famintas. A desordem e a falência de engenhos levaram o governo local a alterar a lei, permitindo a emigração de trabalhadores. Naqueles anos, o maior número de emigrantes partiu para a Guiana Inglesa, onde as recentes políticas de colonização abriam áreas de trabalho nas áreas urbanas, como policiais ou artesãos (ALLEYNE, 2019).

Seguindo as recomendações da comissão criada para investigar os problemas sociais da ilha - após vários incidentes de levantes e saques de fazendas - foi aprovado o Education Act, recomendando a educação de todas as crianças abaixo de 12 anos. A lei criou em pouco tempo um seguimento populacional que se destacava por ser alfabetizado. Em 1877, teve início a construção de uma ferrovia que ligava diferentes pontos em Barbados, inaugurada em 1881, abrindo a possibilidade de emprego fora das fazendas. Em 1882 foi a vez da construção das linhas de bonde em Bridgetown. A vida dava sinais de melhora.

A experiência na construção da estrada de ferro e dos bondes, apesar de terem trajetos relativamente curtos, contribuiu para formar uma mão-de-obra especializada na construção e posteriormente operação e manutenção de tais projetos. $\mathrm{O}$ fato de alguns desses trabalhadores serem alfabetizados foi outro diferencial em favor dos emigrantes. Muitos foram empregados em construções semelhantes, no Canal do Panamá, na Costa Rica e até mesmo no Brasil, entre 1900 e 1920. No Brasil, o número de trabalhadores imigrantes provenientes de Barbados não tem significância numérica quando comparado à onda migratória destinada ao Panamá, Inglaterra, Estados Unidos da América, Guiana Inglesa e Canadá (ROCHA e ALLEYNE, 2012; ALLEYNE 2019). A atração por melhores salários, pagamentos em dólares americanos e a familiaridade com o idioma (no caso dos Estados Unidos), além da facilidade de trânsito entre

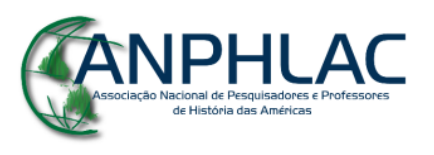

Revista Eletrônica da ANPHLAC, ISSN 1679-1061, № 27, p. 37-65, Ago./Dez., 2019.

http://revista.anphlac.org.br 
portos da costa oeste dos Estados Unidos e Barbados, e entre Panamá e Barbados, foram fatores determinantes para que um maior número de Barbadianos se dirigisse àqueles países (NEWTON, 2004; SENIOR, 2014). Paralelamente, trabalhadores não especializados continuavam a emigrar para trabalhar nas lavouras da América Central, como Costa Rica, Honduras e Belize, nos Estados Unidos da América, Cuba e Porto Rico (HARPELLE 2001; CHOMSKY, 1996; SIMPSON, 2009; MARSHALL, 2016).

Os trabalhadores emigrados continuaram a contribuir financeiramente com suas famílias em Barbados. Aliás, uma das condições para se conseguir o visto de emigração era provar que o viajante possuía vínculos familiares em Barbados. O dinheiro enviado via serviço de correios era essencialmente utilizado em dois projetos: a compra de um terreno para construir a casa própria e a educação de um dos membros mais jovens da família. O objetivo maior era a conquista da liberdade definitiva, rompendo com as relações de exploração estabelecidas pelas plantations (NEWTON, 2004; BECKLES, 2004; RICHARDSON, 1985; ALLEYNE, 2019).

O movimento emigratório influenciou definitivamente a história de Barbados em todos os âmbitos: social, político, econômico e cultural. Demograficamente também houve grandes alterações: entre 1860 e 1920, mais de 150 mil pessoas deixaram a ilha (ROBERTS, 1955). Em 1911 a população barbadiana contava 171.983 pessoas, dez anos depois esse total havia caído para 156.312 habitantes.

Apesar de que a drástica redução de trabalhadores masculinos nas fazendas deveria ter provocado um aumento nos salários, fazendeiros puderam prevenir tal aumento empregando mulheres para executar o que havia se tornado "trabalho de homem" por um valor abaixo do que os homens em geral conseguiam. Mulheres negras, que haviam aproveitado algumas oportunidades para se livrarem do trabalho braçal mais árduo depois da abolição, acharam-se numa situação em que não podiam recusar o pagamento que o trabalho nas roças oferecia, e continuaram a ser o sexo dominante nas gangues de trabalho... (BECKLES, 2006, p. 209)

As emigrações, contudo, tiveram enorme impacto na qualidade de vida dos barbadianos. Além do investimento do dinheiro remetido na compra da casa e ou do terreno para a família, e dos investimentos na educação dos mais jovens, houve muitos casos de retorno de pessoas que foram trabalhar no Panamá, nos Estados Unidos, em Cuba e em outros países, e também dos que foram para a Europa alistados como soldados no Exército Real. Junto aos que retornavam, vinham novas ideias, propostas de liberdade e de direitos políticos,

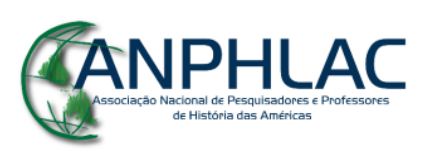


investimentos em novos negócios, elementos que tiveram como resultado final a construção de uma nova classe média intelectual e politizada.

\section{Mudanças Sociais e Acesso à Moradia}

Entre 1937 e 1938, várias rebeliões acontecem nas ilhas caribenhas, causadas pelos efeitos da crise econômica e pelas condições de pobreza da maioria da população. Barbados foi uma das colônias onde tais rebeliões aconteceram. Na apuração dos fatos que levaram aos distúrbios sociais, a Coroa Inglesa acabou por reconhecer os relatórios das comissões de investigação que apontaram para a miséria, pobreza, condições precárias de moradia, insalubridade e baixa qualidade de vida como fatores causadores das revoltas. Entre as medidas para sanar a situação estava a colocação de mais lotes de terras no mercado a serem vendidos em condições acessíveis aos trabalhadores negros e a expansão do sistema de educação pública, criando mais oportunidades para as meninas frequentarem a escola.

O trânsito de pessoas e ideias entre Barbados e os Estados Unidos e Inglaterra levou para a ilha propostas políticas de integração social e antirracismo. Desde o jamaicano Marcus Garvey, que se opunha às ideologias que pregavam a superioridade dos brancos nas décadas de 1920 e 30 e reivindicava direitos econômicos e políticos para os negros, aos discursos de Martin Luther King, Stokely Carmichael e Malcolm X nos anos 60, aliados à retórica africana em sua luta pela independência. Dessa maneira, a classe trabalhadora e intelectual de Barbados (assim como em outras partes do Caribe) passou a reivindicar seus direitos de forma mais ostensiva. Paralelamente, a decadência da cultura da cana-de-açúcar deu lugar à economia do turismo e a uma nova classe empreendedora, desligada da oligarquia. $\mathrm{O}$ setor de serviços cresceu, levando ao surgimento de mais oportunidades de trabalho.

Os projetos para a construção e financiamento de moradias populares destinadas à população de baixa renda começaram a surgir na década de 1950, aproveitando terras abandonadas ou vendidas a baixo custo pelo latifúndio improdutivo. As antigas free villages se desenvolveram com o aumento da renda de seus moradores e o investimento dos emigrantes empenhados em ajudar suas famílias.

A independência política, em 1966, trouxe o desenvolvimento da infraestrutura, ampliando o sistema de esgoto, água encanada e luz para bairros mais pobres e a abertura de

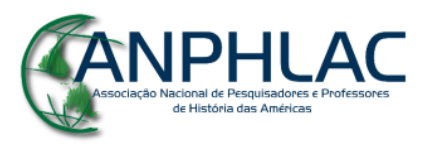

Revista Eletrônica da ANPHLAC, ISSN 1679-1061, № 27, p. 37-65, Ago./Dez., 2019.

http://revista.anphlac.org.br 
ruas, assim como a construção de mais casas populares. Estudo revelam grandes avanços entre 1970 e 1990, com mais construções apoiadas por financiamento internacional. Os novos proprietários também investiram em suas casas, ampliando a construção ou promovendo melhorias na estrutura. Gradativamente as casas de madeira foram sendo substituídas por alvenaria, ainda que continuem sendo comuns as casas de madeira no estilo que se tornou tradicional da ilha: as chattel houses (WATSON \& POTTER, 2001).

Após a independência, grande parte do compromisso da nova liderança política se concentrou na expansão gradativa do sistema educacional, abrindo escolas em cada distrito ou paróquia e facilitando o acesso das crianças à escola gratuita. Os melhores salários propiciaram às famílias maior estabilidade e a possibilidade de pouparem seus filhos do trabalho precoce. Uma forte classe média negra surgiu na ilha, ascendendo rapidamente a níveis mais altos, contando para isso com a educação universitária.

Em 1963, a University of the West Indies estabeleceu um campus em Barbados para atender à demanda dessa classe média, oferecendo também condições para o acesso da classe trabalhadora. A princípio, bolsas de estudo para pós-graduação eram oferecidas aos melhores alunos para completarem seus estudos na Inglaterra, com isso se formou uma inteligentsia regional preocupada com assuntos mais diretamente relacionados à sua realidade. Atualmente, pode-se dizer que mais de $80 \%$ dos professores, em sua grande maioria doutores e mestres, são negros. Entre estes, a maioria é originária de Barbados ou das ilhas vizinhas, já outros são professores originários de países como a Nigéria, Congo e Gana. Tal dado é importante porque influencia o modo de pensar e agir da sociedade em geral, impondo distância entre o tempo em que deveriam se conformar com sua posição subalterna e a atualidade, na qual a presença de negros entre a elite intelectual, social, política e econômica não causa qualquer estranhamento.

A crise de moradia em Barbados ainda não foi completamente resolvida, havendo demanda para a construção de mais casas populares. O país, porém, se situa entre os mais desenvolvidos e com mais elevado índice de educação do continente. A luta pela moradia no Pós-Abolição em Barbados durou mais de cem anos e pode ser considerada como uma extensão da luta pela liberdade, buscando extinguir de vez as peias da escravidão. As conquistas sociais se deram em confluência com avanços políticos e econômicos e têm sido parte importante da história desse povo orgulhoso de suas raízes e sua trajetória. A ilha ainda possui o metro

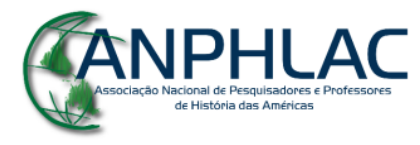

Revista Eletrônica da ANPHLAC, ISSN 1679-1061, № 27, p. 37-65, Ago./Dez., 2019.

http://revista.anphlac.org.br 
quadrado mais caro da região, porém o número de habitantes sem teto é o menor da mesma região, resultado da pressão popular e da proximidade entre políticos e a comunidade.

\section{Referências Bibliográficas}

ALLEYNE, F. Barbadian Migration to British Guiana and Brazil 850-1950. A Comparative Study. Tese de Doutorado. University of the West Indies, campus Cave Hill, Barbados, 2019.

ANDREWS, G. Afro-Latin America 1800-2000. New York: Oxford University Press, 2004.

BANTON, C. "Realms of Freedom in Post-Emancipation Barbados. In: LANDSCAPES of FREEDOM, Conference paper. Pennsylvania State University's Richards Civil War Era Center, 02 abril, 2011.

BANTON, C. More Auspicious Shores: Barbadian Migration to Liberia. Blackness and the Making of an African Republic. New York: Cambridge, 2019.

BECKLES, H. A History of Barbados: from Amerindian Settlement to Caribbean Single Market. New York: Cambridge University Press, 2006.

BECKLES, H. Great House Rules. Landless Emancipation and Worker's Protest in Barbados 1838-1938. Kingston, Jamaica: Ian Randle Publishers, 2004.

BECKLES, H. Natural Rebels: A Social History of Enslaved Black Women in Barbados. New Brunswick: Rutgers University Press, 1989.

BECKLES, H. Property Rights in Pleasure: the Marketing of Enslaved Women's Sexuality. In: BECKLES, H.; SHEPHERD V. (orgs.). Caribbean Slavery in the Atlantic World. Kingston: Ian Randle Publishers/ Oxford: James Currey Publishers/ Princetown: Marcus Wiener Publishers, 1999, p. 692-701.

BELLE, G. The Abortive Revolution of 1876 in Barbados. In: BECKLES, H.; SHEPHERD, V. (orgs.). Caribbean Freedom: Economy and Society from Emancipation to Present. Kingston, Jamaica: Ian Randle Publishers, 1996, p. 181-191.

BRODNER, E. The Second Generation of Freemen in Jamaica, 1907-1944. Gainesville: University Press of Florida, 2004.

BROWN, L.; INNISS, T. Slave Women, Family Strategies and the Transition to Freedom in Barbados, 1834-1941. In: CAMPBELL, G.; MIERS, S.; MILLER, J. (orgs.). Women and Slavery: The Modern Atlantic v.2. Athens: Ohio University Press, 2008, p. 172-185.

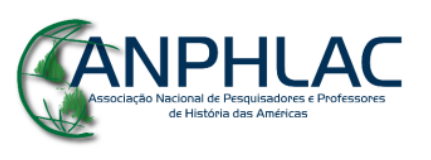


BROWNE, D. Political Awakening in Bridgetown: the Wickham/O'Neal years. In: MARSHALL, W.; WELCH, P. (orgs.) Beyond the Bridge: A series of Lectures to Commemorate the $375^{\text {th }}$ Anniversary of Bridgetown. Bridgetown: Barbados Museum and Historical Society/Dept. of History and Philosophy, UWI/Cave Hill, 2005, p. 272-288.

BROWNE, D. Race, Class, Politics and the Struggle for Empowerment in Barbados 19141937. Kingston, Jamaica: Ian Randle Publisher, 2012.

BRYAN, P. República Dominicana, 1870-1916. Aspectos Socioeconômicos e Ideológicos das Plantations de Mão-de-Obra Livre. In: ROCHA, E.; SILVA, L.; REIS, T. (orgs.). Mundos do Trabalho e dos Trabalhadores. Experiências e Vivências no Brasil e no Caribe. Rio de Janeiro: Multifoco, 2018, p. 137-173.

BUTLER, K. Freedoms given, freedoms won. Afro-Brazilians in post-abolition São Paulo e Salvador. New Jersey: Rutgers University Press, 1998

CARTER, H. Labour Pains: Resistance and Protest in Barbados 1838-1904. Kingston: Jamaica: Ian Randle Publishers, 2012.

CARTER, H. Labour Riots in Bridgetown in the Late Nineteenth Century. In: MARSHALL, W.; WELCH, P. (orgs.) Beyond the Bridge: a Series of Lectures to Commemorate the $375^{\text {th }}$ Anniversary of Bridgetown. Bridgetown: Barbados Museum and Historical Society/Dept. of History and Philosophy, UWI/Cave Hill, 2005, p. 248-271.

CHOMSKY, Aviva. West Indian Workers and the United Fruit Company in Costa Rica, 1870-1940. Baton Rouge: Louisiana State University Press, 1996.

COSTA, C.E. De Pé Calçado: Família, Trabalho e Migração no Pós-Abolição da Baixada Fluminense, RJ. (1888-1940). Tese de Doutorado. Rio de Janeiro, 2013.

FONER, E. Reconstruction, America's Unfinished Revolution 1863-1877. New York: Harper \& Row, 2014.

FONER, E. A Short History of Reconstruction. New York: Harper \& Row, 2014.

FORTES, Alexandre; MATTOS, Hebe. APRESENTAÇÃO. Revista Brasileira de História, São Paulo, v. 35, n. 69, p. 7-10, jun. 2015. Disponível em <www.scielo.br/scielo.php?script=sci_arttext\&pid=S0102-01882015000100007\&lng=pt\&nrm=iso>. Acesso em 26 julho, 2019.

FRANKLIN, J.H. From Slavery to Freedom: a History of African Americans, 1st ed. New York: A.A. Knopf, 1947.

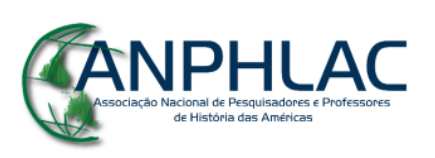


FRANKLIN, J.H.; MOSS Jr., A. From Slavery to Freedom: a History of African Americans, 8a. ed., New York: Random House, 2000.

FRANKLIN, J.H.; HIGGINBOTHAM, E., From Slavery to Freedom: a History of African Americans, 9a.ed. New York: McGraw-Hill Education, 2010.

GREENFIELD, S. English Rustics in Black Skin: a Story of Modern Family Forms in a PreIndustrialized Society. Bridgetown: Barbados Museum and Historical Society, 2010.

HARPELLE, R. The West Indians of Costa Rica: Race, Class and the Integration of an Ethnic Minority. Kingston: McGill-Queens University Press, 2001.

HIGMAN, B.W. A Concise History of the Caribbean. New York: Cambridge, 2011.

INNISS, T. "This Complicated Incest": Children, Sexuality, and Sexual Abuse during Slavery and Apprenticeship Period in the British Caribbean, 1790-1838. In: CAMPBELL, G. e ELBOURNE, E. (orgs.). Sex, Power and Slavery. Athens: Ohia University Press, 2014, p. 253271.

MARSHALL, S. Tell my Mother I Gone to Cuba. Stories of Early Twentieth-Century Migration from Barbados. Kingston: The University of the West Indies Press, 2016.

MARSHALL, Woodville. Notes on Peasant Development in the West Indies since 1838. In: BECKLES, H.; SHEPHERD, V. (orgs.). Caribbean Freedom: Economy and Society from Emancipation to Present. Kingston, Jamaica: Ian Randle Publishers, 1996, p. 99-106.

NEWTON, V. Silvermen: West Indian Labor Migrations to Panama 1850-1914. Kingston: Ian Randle Publishers, 2004.

PACKARD, J. American Nightmare: The History of Jim Crow. New York: St Martin's Press, 2003.

RICHARDSON, B. Panama Money in Barbados. Knowville: University of Tennessee Press, 1985.

ROBERTS, G. W. Emigration from the Island of Barbados. Social and Economic Studies v.4, n. 3, p. 245-188, University of the West Indies, Kingston, 1955. Disponível em: http://www.jstor.org/stable/27851027. Acesso em 18 fev. 2016.

ROCHA, Elaine; ALLEYNE, F. Millie Gone to Brazil. Barbadian Migration to Brazil in Early $20^{\text {th }}$ century. Journal of the Barbados Museum and Historical Society, v. 58, p. 1-42, Bridgetown, dez. 2012.

SCHOMBURGK, R. The History of Barbados. Oxon, UK: Frank Class, 1848, reimpresso em 2005.

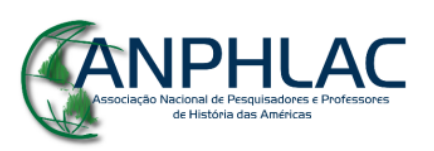

Revista Eletrônica da ANPHLAC, ISSN 1679-1061, № 27, p. 37-65, Ago./Dez., 2019.

http://revista.anphlac.org.br 
SENIOR, O. Dying to Better Themselves: West Indians and the Building of the Panama Canal. Kingston: University of the West Indians Press, 2014.

THOMAS-HOPE. E. (ed.) Freedom and Constraint in Caribbean Migration. Kingston: Ian Randle Publishers, 2009.

SIMPSON, Victor. Harnessing a critical resource: Black West Indian migration to Puerto Rico during the eighteenth and nineteenth centuries. The Journal of the Caribbean History, v. 43, n. 1, 2009.

THOME, J.; KIMBALL, H. Emancipation in the West Indies. A Six Months Tour in Antigua, Barbadoes and Jamaica in the year 1837. New York: The American Anti-Slavery Society, 1838.

WATSON, M. e POTTER, R. Low-Costing Housing in Barbados: Evolution or Social Revolution. Kingston: University of the West Indies Press, 2001.

WILKERSON, I. The Warmth of Other Suns: The Epic Story of America's Great Migration. New York: Random House, 2010.

WOODWARD, C.Vann. The Strange Career of Jim Crow. New York: Oxford University Press, 2002.

YATES, A. W. Bygone Barbados. Bridgetown: Black Bird Studios, 1998.

\section{GANPHLAC}

Revista Eletrônica da ANPHLAC, ISSN 1679-1061, № 27, p. 37-65, Ago./Dez., 2019.

http://revista.anphlac.org.br 